\title{
Loss of expression of FANCD2 protein in sporadic and hereditary breast cancer
}

\author{
Petra van der Groep • Michael Hoelzel • \\ Horst Buerger · Hans Joenje · Johan P. de Winter • \\ Paul J. van Diest
}

Received: 21 September 2006/ Accepted: 30 January 2007 / Published online: 27 February 2007

(C) Springer Science+Business Media B.V. 2007

\begin{abstract}
Fanconi anemia (FA) is a recessive disorder associated with progressive pancytopenia, multiple developmental defects, and marked predisposition to malignancies. FA is genetically heterogeneous, comprising at least 12 complementation groups (A-M). Activation of one of the FA proteins (FANCD2) by mono-ubiquitination is an essential step in DNA damage response. As FANCD2 interacts with BRCA1, is expressed in proliferating normal breast cells, and FANCD2 knockout mice develop breast tumors, we investigated the expression of FANCD2 in sporadic and hereditary invasive breast cancer patients to evaluate its possible role in breast carcinogenesis. Two tissue microarrays of 129 and 220 sporadic breast cancers and a tissue microarray containing 25 BRCA1 germline mutation-related invasive breast cancers were stained for FANCD2. Expression results were compared with several clinicopathological variables and
\end{abstract}

Petra van der Groep and Michael Hoelzel contributed equally to this study.

P. van der Groep $(\varangle)$. P. J. van Diest

Department of Pathology, University Medical Center,

Utrecht, The Netherlands

e-mail: P.J.vanDiest@azu.nl

M. Hoelzel

Department of Pathology, VU University Medical Center, Amsterdam, The Netherlands

H. Buerger

Institute of Pathology, University of Muenster, Muenster, Germany

H. Joenje · J. P. de Winter

Department of Human Genetics, VU University Medical

Center, Amsterdam, The Netherlands tested for prognostic value. Eighteen of 96 (19\%) sporadic breast cancers and two of $21(10 \%)$ BRCA1related breast cancers were completely FANCD2negative, which, however, still showed proliferation. In the remaining cases, the percentage of FANCD2expressing cells correlated strongly with mitotic index and percentage of cells positive for the proliferation markers Ki-67 and Cyclin A. In immunofluorescence double staining, coexpression of FANCD2 and Ki-67 was apparent. In survival analysis, high FANCD2 expression appeared to be prognostically unfavorable for overall survival $(p=0.03)$, independent from other major prognosticators $(p=0.026)$. In conclusion, FANCD2 expression is absent in 10-20\% of sporadic and BRCA1-related breast cancers, indicating that somatic inactivating (epi)genetic events in FANCD2 may be important in both sporadic and hereditary breast carcinogenesis. FANCD2 is of independent prognostic value in sporadic breast cancer.

Keywords Breast cancer - FANCD2 . Immunohistochemistry · BRCA1 · Prognosis ·

Proliferation

\section{Introduction}

Fanconi anemia (FA) is a recessive disease with both autosomal and $\mathrm{X}$-linked inheritance. FA is associated with progressive pancytopenia, developmental defects, and marked predisposition to malignancies, especially acute myeloid leukemia and squamous cell carcinoma of the head and neck $[1,2]$. FA cells are characterized by spontaneous chromosomal instability and hypersensitivity to DNA cross-linking agents such as mitomycin 
$\mathrm{C}$ (MMC). FA is genetically heterogeneous and comprises at least 12 complementation groups (A-M). Eleven of the FA genes have been identified so far: FANCA, FANCB, FANCC, FANCD1/BRCA2, FANCD2, FANCE, FANCF, FANCG, FANCJ, $F A N C L$, and FANCM [3-18]. Eight FA proteins (A, $\mathrm{B}, \mathrm{C}, \mathrm{E}, \mathrm{F}, \mathrm{G}, \mathrm{L}$, and $\mathrm{M}$ ) form a nuclear protein complex which is required for mono-ubiquitination of the downstream FA protein, FANCD2. Activation of FANCD2 by mono-ubiquitination is an essential step in the DNA damage response induced by MMC or ionizing irradiation [2, 10]. This DNA damage response pathway also includes the breast cancer susceptibility genes $B R C A 1$ and $B R C A 2$, also referred to as the FA-BRCA pathway. Following ionizing radiation, FANCD2 and BRCA1 accumulate and colocalize in nuclear foci, which reflect sites of DNA damage and repair $[10,19]$. Like FA cells, cells lacking BRCA1/2 proteins are hypersensitive to DNA crosslinking agents. D'Andrea et al. showed that FANCD1 and BRCA2 are the same proteins. BRCA2 is a direct regulator of RAD51, a protein essential for homologous recombination repair [20]. Although BRCA1 is mainly involved in hereditary breast cancer [21], it has also been implicated in sporadic breast cancer [22]. In an immunohistochemical analysis, we have previously shown that FANCD2 is expressed in proliferating cells of different organs, including the premenopausal breast duct epithelium [23]. This is in line with the role of FANCD2 in DNA repair which is important to guarantee the integrity of the genome during cell replication [10]. As deregulation of proliferation is one of the crucial processes of carcinogenesis, these observations imply a potential role for FANCD2 in the pathogenesis of breast cancer. Indeed, FANCD2 knockout mice develop breast tumors [24]. These considerations prompted us to investigate the expression of FANCD2 in sporadic and hereditary invasive breast cancers by immunohistochemistry in relation to several other proliferation-related biomarkers and survival.

\section{Materials and methods}

\section{Tissue microarray}

Paraffin blocks containing formaldehyde-fixed breast cancer tissues of 129 cases of invasive breast cancer not selected for family history (further denoted "sporadic") were obtained from the archives of the Department of Pathology of the VU University Medical Center, Amsterdam. For all breast cancer cases, age, lymph node status, and tumor size were docu-
Table 1 Patient characteristics and histology of 120 sporadic and hereditary breast cancers

\begin{tabular}{|c|c|c|c|}
\hline & Sporadic & BRCA1 mutation & Total \\
\hline No. of patients & 96 & 24 & 120 \\
\hline \multicolumn{4}{|l|}{ Age } \\
\hline Mean & 65 & 42 & 62 \\
\hline \multicolumn{4}{|c|}{ Lymph node status } \\
\hline Negative & 58 & 9 & 67 \\
\hline Positive & 38 & 11 & 49 \\
\hline \multicolumn{4}{|l|}{ Tumor size } \\
\hline Mean & 2.34 & 2.78 & 2.40 \\
\hline \multicolumn{4}{|l|}{ Histological type } \\
\hline Ductal & 85 & 17 & 102 \\
\hline Lobular & 7 & 1 & 8 \\
\hline Medullary & 1 & 2 & 3 \\
\hline Tubular & 1 & - & 1 \\
\hline Cribriform & 1 & - & 1 \\
\hline Apocrine & 1 & - & 1 \\
\hline Metaplastic & - & 4 & 4 \\
\hline
\end{tabular}

mented. A second array block was constructed containing 24 cases with a proven BRCA1 germline mutation identified through the Family Cancer Clinic of the VU University Medical Center as previously described [25]. Patient characteristics are shown in Table 1. The hematoxylin-eosin stainings were used to identify representative areas of tumor tissue in the blocks. A tissue microarray was then constructed by transferring tissue cylinders of $4-5 \mathrm{~mm}$ from the representative tumor area of each donor block to the recipient block using a tissue arrayer (Beecher Instruments, Sun Prairie, WI, USA) as described before [26]. A third tissue array block of 220 sporadic breast cancer patients with long-term follow-up was obtained from the archives of the Gerhard-Domagk Institute of Pathology, University of Muenster, as previously described [27].

Sections of $4 \mu \mathrm{m}$ were cut and transferred on SuperFrost+ (Menzel\&Glaeser, Germany) slides for immunohistochemistry. Use of anonymous or coded left over material for scientific purposes is part of the standard treatment contract with patients in our hospital [28].

\section{Immunohistochemistry}

Immunohistochemical analysis had been previously performed on conventional sections for the following markers: Ki-67, Cyclin A, p21, p27, p53, estrogen receptor (ER), progesterone receptor (PR), HER-2/ $n e u$, and EGF-receptor [29]. 
Rabbit polyclonal antiserum against FANCD2 was generated as previously described [23]. Tissue sections were deparaffinized and rehydrated. Endogenous peroxidase was blocked with methanol $/ 0.3 \% \quad \mathrm{H}_{2} \mathrm{O}_{2}$ $(20 \mathrm{~min})$. Sections were heated $\left(30 \mathrm{~min}, 120^{\circ} \mathrm{C}\right)$ in $0.1 \mathrm{M}$ citrate buffer $\mathrm{pH}$ 6. Unspecific binding was blocked with a 1:50 normal goat serum in PBS pH 7.4/ $1 \%$ BSA. Polyclonal rabbit anti-FANCD2 $(200 \mu \mathrm{g} / \mathrm{ml})$ was diluted 1:500 in $\mathrm{PBS} / 1 \% \mathrm{BSA}$, and sections were incubated overnight $\left(4^{\circ} \mathrm{C}\right)$ in a humidified chamber. Subsequently, sections were incubated with HRPconjugated secondary antibodies (EnVision, DAKO) and diaminobenzidin (10 min), counterstained with hematoxylin (20 s), dehydrated, and cover-slipped. Appropriate positive controls were used throughout, and negative controls were obtained by omission of the primary antibodies.

Percentages of positively stained nuclei were estimated by an experienced observer (P.J.v.D.), except for HER-2/neu and EGF-receptor where membrane staining was scored as positive. In addition, FANCD2 intensity was scored semiquantitatively as $0-3$, and an FANCD2 score was calculated for each case by multiplying the \% FANCD2-positive cells by the staining intensity.

For FANCD2/Ki-67 double staining, anti-FANCD2 was diluted 1:150, incubated overnight, followed by incubation with swine anti-Rabbit HRP 1:200 (Dako, Glostrup, Denmark), and detected with the TSA ${ }^{\mathrm{TM}}$ Tetramethylrhodamine system (PerkinElmer Life Sciences, Boston, USA). This was immediately followed by incubation with mouse anti-Ki-67 1:50 (MIB1, Immunotech, Marseille, France) followed by rabbit anti-mouse FITC 1:40 (Dako, Glostrup, Denmark). Nuclei were counterstained by incubation with TO-PRO-3 (Molecular Probes, Eugene, OR, USA) 1:5,000 as previously described [30].

\section{Statistics}

Bivariate scatter plots were generated between the percentage of FANCD2-expressing cells and the other continuous features. For the proliferation-associated features Ki-67, Cyclin A, and MAI, the cases with no FANCD2 expression were excluded from the analysis, assuming that FANCD2 is, by some mechanisms, no longer expressed in these cases. By linear regression analysis, the correlation coefficient $R$ and related $p$ values were calculated. Student's $t$ test was used to compare FANCD2 expression levels between the lowlevel vs. high-level groups for HER-2/neu, the EGFreceptor, ER (cut off 10\%) and PR (cut off 10\%), p53 (cut off 10\%), and Cyclin D1 (cut off 5\%). Prognostic value of FANCD2 (Muenster cases) was assessed by computing Kaplan-Meier curves, and differences between the curves were evaluated with the log-rank test. Multivariate survival analysis was performed by Cox regression.

\section{Results}

Successful FANCD2 staining was performed in 96 of the 129 cases of the VUmc sporadic array block. The drop outs were caused by damaged or detached cores during cutting, mounting, or staining, or did not contain tumor. Eighteen of these cases (19\%) were completely FANCD2-negative. The other cases showed variable staining from 1 to $85 \%$ of the nuclei. In 21 of the 24 BRCA1 cases, FANCD2 staining was performed successfully. In two of these (9.5\%), FANCD2 expression was completely negative. Figure 1 shows some representative examples of FANCD2 staining.

The mean percentage of FANCD2-expressing cells was significantly higher in ER-negative patients $(p=0.019)$, PR-negative patients $(p=0.016)$, EGFRpositive patients $(p=0.002)$, Cyclin-D1-negative patients $(p=0.002)$, and p53-positive patients $(p<0.001)$ (Table 2$)$. No statistically significant difference was seen for HER-2/neu. When analyzing the sporadic and hereditary subgroups, similar associations were seen. FANCD2 staining intensity yielded no useful correlations and no prognostic value, and the FANCD2 score yielded essentially the same correlations and prognostic value as the \% FANCD2-positive cells (data not shown).

In linear regression analysis (Table 3), the percentage of FANCD2-expressing cells was significantly positively correlated to Ki-67 $(R=0.502, p<0.0001)$, Cyclin A $(R=0.482, p<0.0001)$, MAI $(R=0.506$, $p<0.001)$, and p53 $(R=0.379, p<0.0001)$, and significantly negatively correlated to age $(R=0.197, p=0.033)$, $\mathrm{ER}(R=0.221, p=0.017)$, and $\mathrm{PR}(R=0.204, p=0.028)$. There was no correlation between FANCD2 and the other continuous features. Figure 2 shows examples of FANCD2/Ki-67 immunofluorescence double staining, underlining the coexpression of FANCD2 and $\mathrm{Ki}-67$ in invasive breast cancers cells. In the Muenster cases, most of these correlations could be reproduced (age: $p=0.063$, Ki-67: $p=0.001$, p53: $p=0.003$, ER: $p=0.034)$. Only $\mathrm{PR}$ was not significant here, and Cyclin A was not performed.

In the regression analysis between the percentages of FANCD2-expressing cells and Ki-67 and Cyclin A, the completely negative FANCD2 cases were excluded. These FANCD2-negative cases had $\mathrm{Ki}-67$ values 
Fig. 1 Examples of FANCD2 staining in sporadic $(\mathrm{A} / \mathrm{B}$, $\mathrm{A}=$ negative control) and BRCA1-related breast cancers $(\mathrm{C} / \mathrm{D}, \mathrm{C}=$ negative control)
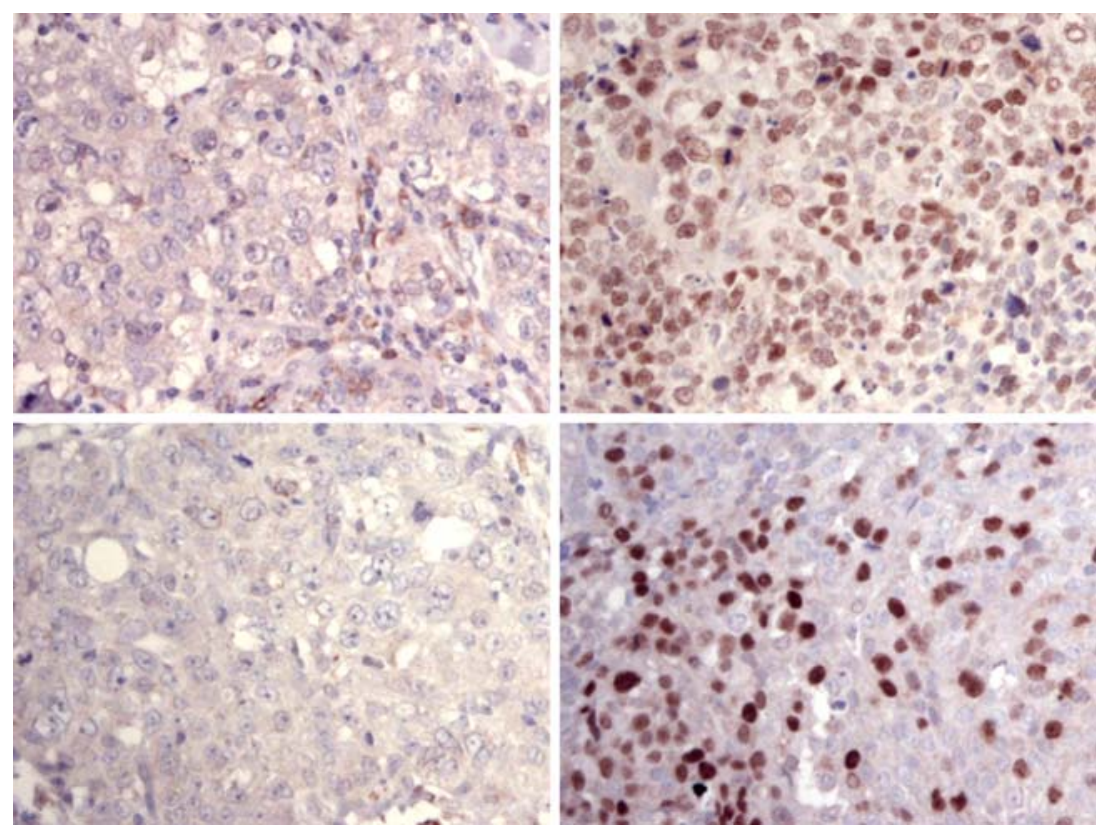

Table 2 Mean percentage of FANCD2-positive cells in highand low-level expression groups of hormone receptors, growth factor receptors, Cyclin D1, and p53 in sporadic and hereditary breast cancers

\begin{tabular}{llll}
\hline & Number $(\%)$ & $\begin{array}{c}\text { Mean }(\mathrm{SE}) \text { of } \\
\text { FANCD2\% }\end{array}$ & $\begin{array}{c}p \text { Value } \\
(t \text { test })\end{array}$ \\
\hline Total & $117(100)$ & & \\
ER & & & \\
$\quad$ Low & $56(48)$ & $14(2.5)$ & 0.019 \\
High & $61(52)$ & $8(1.6)$ & \\
PR & & & 0.016 \\
Low & $81(69)$ & $17(1.9)$ & \\
High & $36(31)$ & $12(1.9)$ & 0.797 \\
HER-2/neu & & & \\
$\quad$ Negative & $93(79)$ & $16(1.6)$ & 0.002 \\
Positive & $24(21)$ & $17(3.5)$ & \\
EGF receptor & & & \\
$\quad$ Negative & $78(66)$ & $13(1.5)$ & 0.002 \\
Positive & $39(33)$ & $19(3.1)$ & \\
Cyclin D1 & & & \\
Low & $85(73)$ & $12(1.9)$ & \\
High & $32(27)$ & $7(2.6)$ & \\
p53 & & & \\
Low & $88(75)$ & $19(4.3)$ & \\
High & $29(25)$ & & \\
\hline
\end{tabular}

$E R$ estrogen receptor, $P R$ progesterone receptor

between 1 and 65 (mean 16\%), Cyclin A values between 0 and 50 (mean 10\%), and MAI values between 0 and 37 (mean 11), indicating that these cases had (sometimes even high) FANCD2-independent proliferation.
Table 3 Correlation between mean percentage of FANCD2expressing cells and other continuous clinicopathological variables in sporadic and hereditary breast cancers

\begin{tabular}{lrr}
\hline Feature & \multicolumn{1}{l}{$R$} & $p$ Value \\
\hline MAI $^{\mathrm{a}}$ & 0.506 & $<0.001$ \\
Ki-67 $^{\mathrm{a}}$ & 0.502 & $<0.001$ \\
Cyclin A $^{\mathrm{a}}$ & 0.482 & $<0.001$ \\
Age & -0.197 & 0.033 \\
ER & -0.221 & 0.017 \\
PR & -0.204 & 0.028 \\
Tumor size & 0.018 & 0.852 \\
p27 & -0.074 & 0.430 \\
p21 & -0.171 & 0.065 \\
p53 & 0.379 & $<0.001$ \\
Cyclin D1 & -0.126 & 0.176 \\
\hline
\end{tabular}

$E R$ estrogen receptor, $P R$ progesterone receptor

${ }^{a}$ FANCD2-negative cases excluded

In survival analysis (sporadic Muenster cases), high FANCD2 expression appeared to be prognostically unfavorable $(p=0.03)$. Figure 3 shows the survival curves. In Cox regression including tumor size, lymph node status, ER, and grade, FANCD2 staining appeared to have independent prognostic value for overall survival $(p=0.026)$.

\section{Discussion}

The aim of this study was to investigate the expression of FANCD2 in sporadic and hereditary breast cancers. This was inspired by several observations. First, FANCD2 and BRCA1/2 are functionally closely linked 

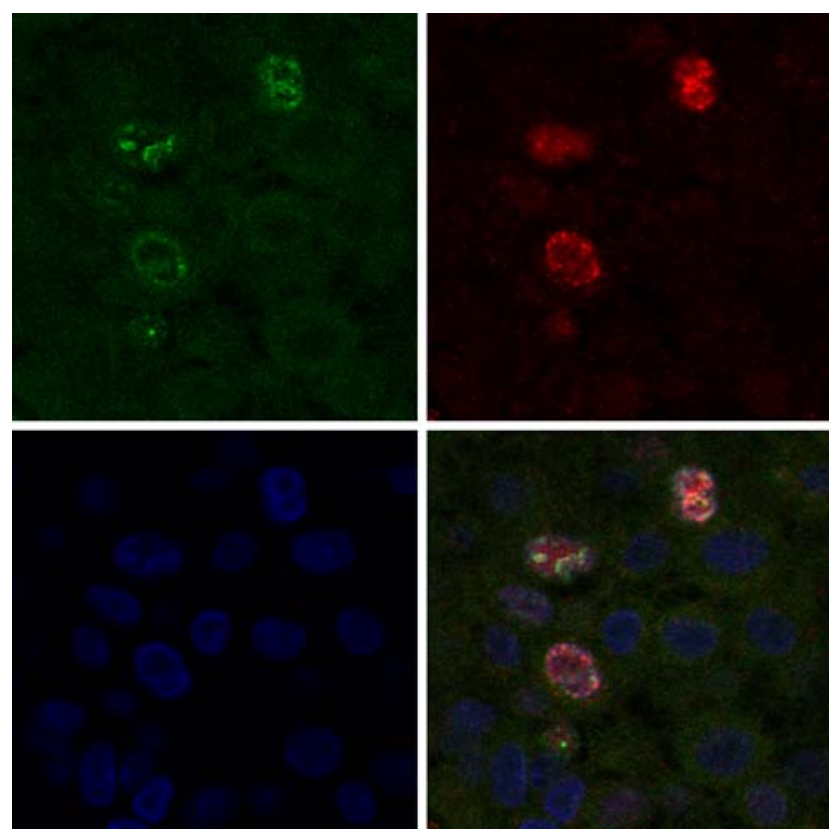

Fig. 2 FANCD2/Ki-67 immunofluorescence double staining in a representative case of invasive breast cancer. Top left: Ki-67 staining. Top right: FANCD2 staining. Bottom left: TO-PRO staining. D: Triple exposure showing coexpression of FANCD2 and $\mathrm{Ki}-67$

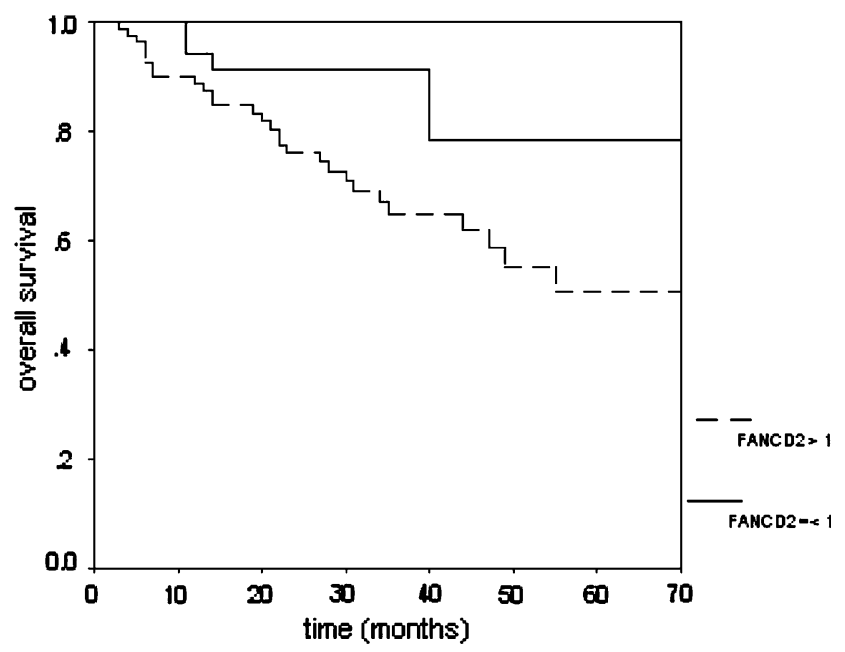

Fig. 3 Prognostic value of FANCD2 expression in sporadic invasive breast cancer. Low expressors have a better survival than high expressors $(p=0.03, N=122)$

in the DNA repair response, and BRCA1 and BRCA2 are implicated in hereditary and sporadic breast cancers [21, 22]. Second, targeted deletion of FANCD2 in mice resulted in an increased rate of breast tumors [24]. Third, we have shown that FANCD2 is expressed in proliferating cells in the duct epithelium of the normal breast [23].
It appeared that $19 \%$ of sporadic breast cancers completely lacked FANCD2 expression. Yet, these FANCD2-negative cases had high mean Ki-67, Cyclin $\mathrm{A}$, and MAI values, indicating that the low FANCD2 levels in these cases cannot be explained by low proliferation. The fact that these FANCD2-negative cases stained for other proteins makes it quite unlikely that the FANCD2 negativity is due to fixation problems. In the FANCD2-negative cases, FANCD2 inactivation may, in view of its important function, have been a hit in carcinogenesis. BRCA1 germline mutation-related breast cancers showed lack of FANCD2 expression in only $9.5 \%$ of cases, which fits with the concept that a major hit in an important pathway (in these cases the BRCA1 germline mutation) is usually not associated with further hits in this pathway. It is yet unclear what the mechanism behind the lack of FANCD2 expression in these cases is. It needs to be further studied whether there are inactivating somatic mutations in these cases or whether promoter methylation plays a role.

FANCD2 expression was strongly correlated with expression of the proliferation-associated features Ki-67, Cyclin A, and MAI, and FANCD2 and Ki-67 were coexpressed in invasive cancer cells. This is likely a reflection of the physiological function of FANCD2 in DNA repair of proliferating cells, rather than an independent overexpression of an altered gene, in line with our previous study where we found a coexpression of FANCD2 and $\mathrm{Ki}-67$ in proliferating cells of various normal human tissues [23]. The observation that high FANCD2 expression indicated poor prognosis fits within the same concept, as rate of proliferation (and thereby FANCD2 expression) is a major cell biological phenomenon determining prognosis [31-33]. FANCD2 had prognostic value independent of stage and grade, which can be explained by the fact that proliferation and stage are not strongly correlated, and that grade includes nuclear atypia and tubule formation besides rate of proliferation as measured by mitotic index.

Although heterozygosity for p53 was shown to accelerate epithelial tumor formation in Fancd2 knockout mice [34], a functional link between p53 and Fancd 2 has not been described to explain the association found in the present study, which is likely caused by the fact that p53 mutated and thereby p53 protein accumulated tumors show, in general, higher proliferation and therefore more proliferating FANCD2-expressing cells. The same may also hold for the relation between FANCD2 and EGFR expressions, for which also no functional relationship has been described.

The negative relation between FANCD2 and age can likely be explained by the fact that BRCA1-related 
patients that have higher FANCD2 expression are younger.

Within the light of the above observations, the question remains why FANCD2 patients do not seem to be predisposed to breast cancer in clinical practice. FA itself is a rare genetic disease where the complementation group D2 constitutes only $1-2 \%$ of all FA cases and these patients generally have a more severe clinical course. They may therefore simply not live to get breast cancer in an apparent increased frequency. Our results do not indicate that somatic (epi)genetic changes in FANCD2 are a frequent secondary carcinogenetic event in BRCA1 germline-mutated patients, although this needs to be confirmed in a larger study group.

In conclusion, FANCD2 expression is absent in 10$20 \%$ of sporadic and BRCA1-related breast cancers, indicating that somatic inactivating (epi)genetic events in FANCD2 may be important in both sporadic and hereditary breast carcinogenesis. FANCD2 is of independent prognostic value in sporadic breast cancer.

Acknowledgments We thank Dick van Wichen, Jurryt van der Gugten, and Lennert Ploeger for their expert help with the immunofluorescence double staining. This work was supported by grants from the Maurits Anna de Kock foundation, the Dutch Organization for Scientific Research and the Dutch Cancer Society (VU2001-2505), and the First Aegon International Scholarship in Oncology.

\section{References}

1. Joenje H, Patel KJ (2001) The emerging genetic and molecular basis of Fanconi anaemia. Nat Rev Genet 2:446-457

2. D'Andrea AD, Grompe M (2003) The Fanconi anaemia/ BRCA pathway. Nat Rev Cancer 3:23-34

3. Timmers C, Taniguchi T, Hejna J et al (2001) Positional cloning of a novel Fanconi anemia gene, FANCD2. Mol Cell 7:241-248

4. Strathdee CA, Gavish H, Shannon WR, Buchwald M (1992) Cloning of cDNAs for Fanconi's anaemia by functional complementation. Nature 356:763-767

5. de Winter JP, Waisfisz Q, Rooimans MA et al (1998) The Fanconi anaemia group G gene FANCG is identical with XRCC9. Nat Genet 20:281-283

6. de Winter JP, Leveille F, van Berkel CG et al (2000) Isolation of a cDNA representing the Fanconi anemia complementation group $\mathrm{E}$ gene. Am $\mathrm{J}$ Hum Genet 67:1306-1308

7. de Winter JP, Rooimans MA, van Der Weel L et al (2000) The Fanconi anaemia gene FANCF encodes a novel protein with homology to ROM. Nat Genet 24:15-16

8. Lo Ten Foe JR, Rooimans MA, Bosnoyan-Collins L et al (1996) Expression cloning of a cDNA for the major Fanconi anaemia gene, FAA. Nat Genet 14:320-323

9. Howlett NG, Taniguchi T, Olson S et al (2002) Biallelic inactivation of BRCA2 in Fanconi anemia. Science 297:606-609

10. Garcia-Higuera I, Taniguchi T, Ganesan S et al (2001) Interaction of the Fanconi anemia proteins and BRCA1 in a common pathway. Mol Cell 7:249-262
11. Waisfisz Q, de Winter JP, Kruyt FAE et al (1999) A physical complex of the Fanconi anemia proteins FANCG/XRCC9 and FANCA. Proc Natl Acad Sci USA 96:10320-10325

12. van de Vrugt HJ, Koomen M, Berns MAD et al (2002) Characterization, expression and complex formation of the murine Fanconi anaemia gene product FANCG. Genes Cells 7:333-342

13. Levitus M, Rooimans MA, Steltenpool J et al (2004) Heterogeneity in Fanconi anemia: evidence for 2 new genetic subtypes. Blood 103:2498-2503

14. Meetei AR, Medhurst AL, Ling C et al (2005) A human ortholog of archael DNA repair protein Hef is defective in Fanconi anemia complementation group M. Nat Genet 37:958-963

15. Meetei AR, Levitus M, Xue Y et al (2004) X-linked inheritance of Fanconi anemia complementation group B. Nat Genet 36:1219-1224

16. Meetei AR, de Winter JP, Medhurst AL et al (2003) A novel ubiquitin ligase is deficient in Fanconi anemia. Nat Genet 35:165-170

17. de Winter JP, van der Weel L, de Groot J et al (2000) The Fanconi anemia protein FANCF forms a nuclear complex with FANCA, FANC and FANCG. Hum Mol Genet 9:2665-2674

18. Fei P, Yin J, Wang W (2005) New advances in the DNA damage response network of Fanconi anemia and BRCA proteins: FAAP95 replaces BRCA2 as the true FANCB protein. Cell Cycle 4:80-86

19. Venkitaraman AR (2004) Tracing the network connecting BRCA and Fanconi anemia proteins. Nature 4:266-276

20. Yuan SS, Lee SY, Chen G, Song M, Tomlinson GE, Lee EY (1999) BRCA2 is required for ionizing radiation-induced assembly of Rad51 complex in vivo. Cancer Res 59:3547-3551

21. Miki Y, Swensen J, Shattuck-Eidens D et al (1994) A strong candidate for the breast and ovarian cancer susceptibility gene BRCA1. Science 266:66-71

22. Thompson ME, Jensen RA, Obermiller PS, Page DL, Holt JT (1995) Decreased expression of BRCA1 accelerates growth and is often present during sporadic breast cancer progression. Nat Genet 9:444-450

23. Hölzel M, van Diest PJ, Bier P et al (2003) FANCD2 protein is expressed in proliferating cells of human tissues that are cancer-prone in Fanconi anemia. J Pathol 201:198-203

24. Houghtaling S, Timmers C, Noll M et al (2003) Epithelial cancer in Fanconi anemia complementation group D2 (Fancd2) knockout mice. Genes Dev 17:2021-2035

25. van der Groep P, Bouter A, van der Zanden R et al (2004) Re: Germline BRCA1 mutations and a basal epithelial phenotype in breast cancer. J Natl Cancer Inst 96:712-713

26. Packeisen J, Korsching E, Herbst H, Boecker W, Buerger H (2003) Demystified tissue microarray technology. Mol Pathol 56:198-204

27. Helms MW, Packeisen J, August C et al (2005) First evidence supporting a potential role for the BMP/SMAD pathway in the progression of oestrogen receptor-positive breast cancer. J Pathol 206:366-376

28. van Diest PJ (2002) No consent should be needed for using leftover body material for scientific purposes. For BMJ 325:648-651

29. Michalides R, van Tinteren H, Balkenende A et al (2002) Cyclin A is a prognostic indicator in early stage breast cancer with and without tamoxifen treatment. $\mathrm{Br} \mathrm{J}$ Cancer 86:402-408

30. Huisman A, Ploeger LS, Dullens HF, Poulin N, Grizzle WE, van Diest PJ (2005) Development of 3D chromatin texture analysis using confocal laser scanning microscopy. Cell Oncol 27:335-345 
31. van Diest PJ, Van der Wall E, Baak JPA (2004) Prognostic value of proliferation in invasive breast cancer: a review. J Clin Pathol 57:675-681

32. van Diest PJ, Baak JPA (1991) The morphometric Multivariate Prognostic Index (MPI) is the strongest prognosticator in premenopausal lymph node negative and lymph node positive breast cancer patients. Hum Pathol 22:326-330

33. Baak JP, van Diest PJ, Voorhorst FJ et al (2005) Prospective multicenter validation of the independent prognostic value of the mitotic activity index in lymph node-negative breast cancer patients younger than 55 years. J Clin Oncol 23:5993-6001

34. Houghtaling S, Granville L, Akkari Y et al (2005) Heterozygosity for p53 (Trp53+/?) accelerates epithelial tumor formation in Fanconi anemia complementation group D2 (Fancd2) knockout mice. Cancer Res 65:85-91 